\title{
The Default Risk: An Empirical Analysis on the Automotive Companies
}

\author{
Anna Paola Micheli \\ University of Cassino and Southern Lazio, Cassino, Italy
}

\begin{abstract}
In Italian companies, especially in small and medium enterprises (SME), the management of financial risks, that is considered out of the core business, has not taken yet the role that it should compete in the logic of value creation that a lot of the company's management argues. Towards risk is witnessing a real cultural rejection, mostly it originated from the widespread belief that its operation is fraught with positive effects only in companies that have particular degrees of complexity, because they are organized in groups or because they operate in markets and different contexts. This was due to an erroneous conception of the value that drives most of the businesses to remain, in fact, and still anchored to traditional forms of management, aimed at maximizing performance accounting. The paper after analyzing the default risk proceeds to calculate the Zeta-score through discriminant analysis of a panel of companies belonging to the automotive sector.
\end{abstract}

Keywords: credit risk, default, automotive companies, discriminant analysis, Zeta-score

\section{Introduction}

Like the effects of the variables of the market, the company, like non-banking firm, is exposed to the default risk of the counterparties, which assumes an active position, by virtue of credits from commercial and/or financial transactions.

About insolvency, the doctrine provides several interpretive keys, some of which are based on a patrimonial approach while others on a financial approach.

For the first, consistency of the assets generates a state of insolvency, when the assets are insufficient to cover liabilities, in a definitive way. If, in fact, that failure was only temporary and due to a liquidity crisis destined to be resolved in the short term, it would be more appropriate to refer to the concept of temporary inability to accomplish rather than talk of insolvency. Therefore, it is a qualifying insolvency based on objective facts and circumstances, which go beyond the specific behavior of the enterprise. The conduct of not paying, in fact, underlies the condition of insolvency, unless it is the result of an irreversible imbalance sheet.

According to second approach, the default would be due to the financial dimension of the enterprises, which, unlike asset, is distinguished by a higher dynamism. So, the firm is insolvent, when it faces a big crisis that produces a significant contraction of liquidity, and it is not able to accomplish obligations.

\footnotetext{
Anna Paola Micheli, Ph.D., research fellow in corporate finance, member of Corporate Finance Lab (FinLab), University of Cassino and Southern Lazio, Cassino, Italy.

Correspondence concerning this article should be addressed to Anna Paola Micheli, Sant' Angelo Road, Cassino, Italy. E-mail: annapaolamicheli@virgilio.it.
} 
In any case, regardless of optics taken, the default state, as pointed out by Sironi, Resti, and Rischio (1999), always presupposes a process of crisis almost irreversible and of a magnitude so large to assume the loss of a significant portion of the credit.

From Merton (1974), the literature that is dedicated to credit risk is widely grown. Considering the works of Black and Cox (1976), Kim, Ramaswamy, and Sundaresan (1993), Longstaff and Schwartz (1995), Anderson and Sundaresan (1996), Jarrow, Lando, and Turnbull (1997), Lando (1998), and Hull and White (2000), a new way of implementation of the Merton model was developed. To estimate the benchmarks, they resort to the observation of the implied volatility of the options of the company. This model is likely to be particularly suitable for companies that have strong off-balance sheet liabilities. Several authors, such as Black and Cox (1976), Geske (1977), Longstaff and Schwartz (1995), Leland and Toft (1996), and Collin-Dufresne and Goldstein (2001), have developed extensions of the Merton model, without any proves superior. Beaver (1966) examined the predictive ability of some indicators with respect to insolvency and concluded that the best predictor of insolvency is the relationship between cash flow and total debt. The indicators that were less able to explain and diagnose insolvencies are due to working capital and liquidity. In the late 60's, discriminant analysis was applied to the work by Altman, Resti, and Sironi (2005) and this kind of analysis was proposed by Fisher in 1936. Some authors then used multivariate models that provide for the application of discriminant analysis (Deakin, 1972; Edmister, 1972; Blum, 1974; Taffler \& Tisshaw, 1977; Bilderbeek, 1979; Micha, 1984; Gombola, Haskins, Ketz, \& Williams, 1987; Lussier, 1995). Altman and Narayanan (1997) developed international models in over 25 countries. Martin (1977) predicted bank failures in 1975/1976 period, using both logit and discriminant analysis. West (1985) measured the financial condition of financial institutions and gave them a probability of default used in the logit model. Lehmann (2003) and Grunert, Norden, and Weber (2005) applied the model using qualitative variables as predictors in the failure prediction model to discriminate between SMEs.

The causes that can lead to insolvency are varied, most of which are directly linked to the economic management of the company.

Sometimes, insolvency is, however, due to exogenous factors to individual companies, affecting system reasons, such as in the case of a sudden financial crisis in the country that precludes any possibility of improving financial transactions with foreign entities. Such exposure, obviously, has a different importance from business to business, considering both the type of activity and the trade policy followed. Exposure to credit risk is obviously more pronounced in banking companies in which credit operations are the core business. However, the exposure is less significant in other companies in which the credit has purely financial nature and it is not tied to any commercial transaction. Ceteris paribus this implies a higher risk than normal operations of merchant credit of other enterprises. However, this does not mean that in non-bank companies, the credit risk is to be considered out of risk management. It is an integral part, but with a different weight depending on the value attributed to the merchant credit, that is a lever to stay on the market, and the degree of dependence on customers, to which are destined sales. If sales are concentrated, the company is exposed on a few customers, whose solvency becomes crucial for the survival of enterprise.

Even in industrial enterprises, therefore, the management company cannot escape the control of credit risk, in its various configurations:

- default risk, due to the impossibility of the client to meet its obligations, in which case it is equal to the difference between the value of the loan and how much it will be actually recoverable; 
- risk of recovery, originated from an erroneous estimate of the recovery rate that at the time of the event of insolvency may be reduced due to complications that occurred in legal proceedings, to the loss of some of the assets provided as collateral;

- risk of spread or migration, when the market value of the credit decreases due to a deterioration in the standing of the counterparty.

\section{The Credit Losses}

For the estimation of credit risk, you must also consider the weight of the expected loss and the unexpected loss. The expected loss is estimated ex ante and it is faceable with specific forms of coverage and/or with a particular price of credit. In fact, if during the concession of an extension of credit, a loss occurs, thanks to a series of alarm indicators, the enterprise may act increasing the price of product of a spread proportional to the lower income estimated ex ante, if market conditions allow. A similar technique of risk management is used in banks, when the unexpected loss is directly charged on the loan conditions applied to the customer. In order to quantify the expected loss, it must remember that expected loss is divided into three elements that are probability of default, the exposure level and, the rate of loss. The relation that links these three elements is the following:

$$
\text { EL }=\text { Default Probability } \times \text { Exposure at Default } \times \text { Loss Given Default }
$$

Therefore, the expected loss is equal to the product of the probability of default, the expected exposure at default and the loss rate associated with the transaction, in particular, the default probability, indicates the probability that, over a certain period of time; the debtor incurs in default, therefore, the inability to meet their commitments; the exposure at default signals the level of loss, as a percentage of total credit, faced by the lender at the end of recovery procedures; the loss given default shows the size of the exposure of the lender, when there is the default of borrower.

Assuming that over a future period, a credit position of 100,000 euro, a default probability of $10 \%$, and a recovery rate of $60 \%$ are estimated, the expected loss will be:

$$
\mathrm{EL}=100,000 \times 10 \% \times 40 \%=4,000
$$

The default probability is estimated aligning the default state with typical situations. The same thing happens in the banking practice in which the insolvency is attributed to the condition of impaired and non-performing. So the default is usually identified with one of the situations between two conditions: the temporary difficulties and the heavy and lasting inability to meet its commitments.

So the definition of default depends on the risk appetite of the company and on its position in relation to the random events. If a prudent attitude prevails, the choice falls on the condition of temporary and objective difficulties, which involves a simple solicitation without legal action, believing that the inability to respect obligations will be solved in short time. On the contrary if, a more aggressive attitude predominates, insolvency is identified by the condition of serious inability, which implies the adoption of legal action in order to have a credit that can be levied.

After the definition of default, its probability can be quantified using the time series of the company, with which it is possible to make predictions about the future or use statistical models about probabilistic evaluation. These last statistic models are treated in the next section.

For now, it should be noted that the probability to refer to estimate the insolvency is neither classical probability, formed by the ratio of the number of cases favorable to the occurrence of the event examined and 
the number of cases equally possible, nor statistical probability, based on the assumption that, given a series of tests carried out under the same conditions, the frequency tends to the probability of the event, with a better approximation increasing the number of test. The first is inapplicable, considering that in the most of economic events, like the insolvency, it is unlikely to verify the equal possibility of occurrence of all cases, that are also difficult to identify in their generality; even the statistical probability is impracticable considering that the solvency is not experienced, because of the continuous dynamic that changes the conditions of the enterprise.

Hence the need to use alternative methods to those purely statistical rejects the isolated observation of the state of solvency of each debtor. Among these, the most frequently used are the analytical subjective models and scoring models. The first focuses their attention on certain items that are able to qualify the creditworthiness of the company, as the history of the company, the amount of credit, credit guarantees, and cash flows generated under certain market conditions. In this context, the analysis is divided into a quantitative side, whose aim is to ascertain the economic and financial condition of debtor, both in the present and in the future, and into a qualitative side, whose goal is to examine the competitive position, considering the sector and macroeconomic scenario.

However, this procedure does not supply a gradation in the level of expected losses and the risk associated with each borrower, it leads to a dichotomous judgment, such as reliable/unreliable, that says little about the probability of default that the enterprise is facing.

About exposure at default, when the exhibition, as usually happens, remains unchanged over time, its value corresponds to the nominal amount of credit. Indeed when this value, over a certain period, is sensitive on the size, as in the lines of credit granted by banks and in the supplier relationships that expect a maximum amount of merchant credit, it is necessary to define the moment in which the default will realistically happen. In fact, it is obvious that considering the current state of difficulty of the customer, this can worsen over time, compounding the exposure of the lender.

As an example, it supposes that a company has entered into a contract with a customer, which establishes the periodic supply of goods with deferred payment and a maximum credit of 500,000 euro. Currently, the credit line is used only in part, for an amount of 100,000 euro. In order to quantify the exposure to the customer, it cannot consider simply the current credit to define the size of the risk. In fact, it is not excluded that the customer will experience financial stress that will push it not to meet deadlines agreed with its suppliers or to divert most of other supplies on contractual relations with the company, in order to defer the time of payment, up to reach the roof merchant credit granted.

Therefore, it is appropriate to monitor systematically the credit positions of the company in order to fix a percentage of the exposure that does not underestimate the real risk. Practically, it is important to estimate the time of failure, considering the approach used by company to define failure and considering the proportion of merchant credit used by the costumer compared to maximum value available.

Finally, as regards to the loss given default, its value depends on the characteristics of the operation set with the customer and on any guarantees associated with the operation. It is also useful to analyze both the patrimonial endowment and legal situation of the subject who receive the credit. In fact, if its patrimonial endowment is bigger, the company will recover more credit.

So as an example, the probability of recovery against corporations is lower than that in a association, due to legal autonomy that characterizes the first; the redraft is limited to the assets of the company, unlike the latter, 
for which recovery is extended even to the assets of the partners, when share capital is insufficient.

It is impossible to estimate full credit risk ex ante, because part of it is derived from sudden lost that the enterprise cannot expect.

The rate of loss really incurred and the recovery rate effectively supported often diverge significantly from the values expected by the company. This indicates that a part of the risk has to be faced and managed with alternative solutions to traditional forms hedge, that are based on the simple consideration of past experience.

In this sense, it speaks of unexpected loss as a measure of variability in the rate of loss compared to the expected value. This, depending on the degree of dispersion of possible loss rates and on the probability of having loss rates higher than expected, is usually estimated with the standard deviation, which, as is known, measures the degree of variability of the results about the respective expected value.

In the last chapter of this work, it will write about the unexpected loss and the exact amount of capital to be allocated to cover unexpected loss.

\section{Discriminant Analysis: An Empirical Study on the Automotive Companies}

Among the different models of measuring the reliability of the borrower, the best known are those of probabilistic nature, as the technique Logit and Probit, expert systems, neural networks, and discriminant analysis. The latter is certainly the model that has the most success among operators, because more information can guarantee results. In his first elaboration, which dates back to Fisher (1936), discriminant analysis aims to correct and place better observations in two sets able to qualify each new observation, through its attribution in a group rather than the other.

With respect to the provisions of the insolvency of the companies, it presupposes, therefore, the exact identification of two groups of companies represented respectively by healthy companies and insolvent companies. This division is achieved by resorting to analysis for clusters, which, as noted, enables the classification of companies, belonging to the universe under investigation, in homogeneous groups with respect to some variables considered relevant.

In particular, on the basis of a similarity index, such as the Pearson correlation coefficient, the group is formed hierarchically or clusters: In the first case, being the group, once formed, no more susceptible of division, it proceeds, by means of successive mergers of the groups less distant between them, to the construction of a single set; in the second case, the units dates are divided into a number of clusters.

Alternatively, the subdivision can be perfect empirically identifying the two sets directly from the observation of reality, by matching the status of anomaly with the status of bankruptcy and the state of normality with the condition of simple and regular activities.

This is a way of proceeding that on one hand it presents the advantage to facilitate the analysis, based on a certain condition; on the other hand, it is little objective, since it groups different companies in an indistinct whole.

For setting the discriminant model, it should, in fact, consider companies that belong to the same sector and have a similar production structure and management, since the membership to different sectors involves differentiation in their respective operating and financial value. In the same way, the membership of dissimilar legal forms produces differences in the compositions of both funding sources and financial needs. 
Practically, the criterion of dividing the undertakings must, however, ensure certain homogeneity of the sets to be defined, in order to elevate the significance of the results of the discriminant analysis, especially with regard to their predictive ability. Special attention has to be addressed, then, the choice of financial ratios, by eliminating, select those indicators that appear not to discriminate sufficiently the default status, since being similar to the two samples of companies. So it is necessary not to consider, for example, those ratios that overlap the healthy companies and insolvent companies, making their classification impossible.

It must therefore share ratios in different categories, in relation to different aspects of the business. It should also reject the ratios that do not ensure a sufficient information, when, for example, it is likely to create a duplication of information, since they are strongly correlated.

Based on these assumptions, the two sets of companies and their economic and business variables allow to qualify the new observation, giving a score representative of his state of health, on the assumption that it replicates in the future as already demonstrated in the past.

The function which is generally applied therefore takes the following form:

$$
Z=a_{1} X_{1}+a_{2} X_{2}+a_{3} X_{3}+a_{4} X_{4}
$$

where $Z$ is the discriminant value calculated for each company; $a$ is the coefficient of discrimination; and $X_{i}$ is the variable.

To give a better idea of the modality of application, the research uses the model shown in the example described below, when it predicts the status of insolvency of a company, after defining the discriminant function. Based on of a sample of 20 enterprises, formed for $50 \%$ by companies in the past, it has proved healthy and $50 \%$ by companies incurred in the condition of default. In particular, the sample consists of 20 companies spreading over the two groups healthy and insolvent. The group is represented by 10 of the failed automotive companies that have been declared bankrupt in 2014, while the others operating in normal conditions in the market.

They were also chosen as explanatory variables of the ratios below, because they have greater capacity information and discriminating:

- ROE (return on equity);

- the current ratio, the ratio of current assets, and current liabilities;

- the incidence of financial charges;

- leverage, i.e., the ratio of payables/banks and total assets.

Compared to these ratios, the 20 companies have shown the values in Table 1 . The coefficients are then calculated on the basis of the following algorithm:

$$
a=\left(\bar{X}_{1}-\bar{X}_{2}\right) S^{-1}
$$

indicating with $\bar{X}_{1}$ and $\bar{X}_{2}$, the vector of the averages of the single variables, relative to the group of healthy companies and to the group of insolvent companies; $S^{-1}$, the inverse matrix of variance and covariance.

First, as shown in Table 2, the averages of the four variables considered (ROE, current ratio, incidence of financial charges, and leverage) were calculated. 
Table 1

Variables for Companies Status

\begin{tabular}{llllll}
\hline & Status & ROE & Current ratio & Incidence of financial charges & Leverage \\
\hline 1 & Healthy & 0.07 & 1.32 & 0.03 & 0.01 \\
2 & Healthy & 0.34 & 1.12 & 0.02 & 0.03 \\
3 & Healthy & 0.25 & 2.33 & 0.04 & 0.04 \\
4 & Healthy & 0.12 & 1.21 & 0.04 & 0.04 \\
5 & Healthy & 0.17 & 2.25 & 0.05 & 0.01 \\
6 & Healthy & 0.20 & 0.73 & 0.02 & 0.01 \\
7 & Healthy & 0.32 & 1.10 & 0.02 & 0.03 \\
8 & Healthy & 0.15 & 1.30 & 0.07 & 0.02 \\
9 & Healthy & 0.09 & 1.50 & 0.03 & 0.06 \\
10 & Healthy & 0.18 & 1.70 & 0.01 & 0.02 \\
11 & Insolvent & -0.05 & 0.56 & 1.34 & 0.45 \\
12 & Insolvent & 0.01 & 0.34 & 1.35 & 0.65 \\
13 & Insolvent & -0.07 & 0.21 & 1.13 & 0.15 \\
14 & Insolvent & 0.02 & 0.55 & 1.57 & 0.47 \\
15 & Insolvent & -0.02 & 0.65 & 1.92 & 0.34 \\
16 & Insolvent & -0.08 & 0.37 & 1.19 & 0.24 \\
17 & Insolvent & -0.03 & 0.45 & 1.37 & 0.62 \\
18 & Insolvent & -0.05 & 0.65 & 1.65 & 0.12 \\
19 & Insolvent & -0.02 & 0.45 & 1.23 & 0.33 \\
20 & Insolvent & -0.06 & 0.12 & 1.56 & 0.21
\end{tabular}

Table 2

Variables Average

\begin{tabular}{lllll}
\hline & ROE & Current ratio & Incidence of financial charges & Leverage \\
\hline Average healthy & 0.189 & 1.456 & 0.033 & 0.027 \\
Average insolvent & -0.021 & 0.435 & 1.431 & 0.358 \\
\hline
\end{tabular}

The values of the average, so determined, were then distributed in the following vectors:

$$
\bar{X}_{1}=\left|\begin{array}{l}
0.189 \\
1.456 \\
0.033 \\
0.027
\end{array}\right| \quad \bar{X}_{2}=\left|\begin{array}{c}
-0.021 \\
0.435 \\
1.431 \\
0.358
\end{array}\right|
$$

To determine, therefore, the matrix $S$, for each variable, the respective variances and covariances have been calculated, as shown in the variance-covariance matrix in Table 3.

Table 3

Variances and Covariances Matrix

\begin{tabular}{lllll}
\hline & $X_{1}$ & $X_{2}$ & $X_{3}$ & $X_{4}$ \\
\hline$X_{1}$ & $\operatorname{Var}\left(x_{1}\right)$ & $\operatorname{Cov}\left(x_{1}, x_{2}\right)$ & $\operatorname{Cov}\left(x_{1}, x_{3}\right)$ & $\operatorname{Cov}\left(x_{1}, x_{4}\right)$ \\
$X_{2}$ & $\operatorname{Cov}\left(x_{2}, x_{1}\right)$ & $\operatorname{Var}\left(x_{2}\right)$ & $\operatorname{Cov}\left(x_{2}, x_{3}\right)$ & $\operatorname{Cov}\left(x_{2}, x_{4}\right)$ \\
$X_{3}$ & $\operatorname{Cov}\left(x_{3}, x_{1}\right)$ & $\operatorname{Cov}\left(x_{3}, x_{2}\right)$ & $\operatorname{Var}\left(x_{3}\right)$ & $\operatorname{Cov}\left(x_{3}, x_{4}\right)$ \\
$X_{4}$ & $\operatorname{Cov}\left(x_{4}, x_{1}\right)$ & $\operatorname{Cov}\left(x_{4}, x_{2}\right)$ & $\operatorname{Cov}\left(x_{4}, x_{3}\right)$ & $\operatorname{Var}\left(x_{4}\right)$ \\
\hline
\end{tabular}

The matrix variances covariances in value became the data in Table 4 . 
Table 4

Variances and Covariances Matrix

\begin{tabular}{lcccc}
\hline & ROE & Current ratio & Incidence of financial charges & Leverage \\
\hline ROE & 0.016 & 0.051 & -0.075 & -0.017 \\
Rapporto corrente & 0.051 & 0.412 & -0.345 & -0.082 \\
Incidenza oneri fin. & -0.075 & -0.345 & 0.542 & 0.115 \\
Leverage & -0.017 & -0.082 & 0.115 & 0.045 \\
\hline
\end{tabular}

The values, so determined, were included in the following matrix:

$$
S=\left|\begin{array}{rrrr}
0.016 & 0.051 & -0.075 & -0.017 \\
0.051 & 0.412 & -0.345 & -0.082 \\
-0.075 & -0.345 & 0.542 & 0.115 \\
-0.017 & -0.082 & 0.115 & 0.045
\end{array}\right|
$$

From which the reverse:

$$
S^{-1}=\left|\begin{array}{rrrr}
164.029 & -2.910 & 19.073 & 7.610 \\
-2.910 & 5.364 & 2.584 & 2.040 \\
19.073 & 2.584 & 7.803 & -7.990 \\
7.610 & 2.040 & -7.990 & 48.792
\end{array}\right|
$$

This matrix multiplied by the vector difference $\left(\bar{X}_{1}-\bar{X}_{2}\right)$, is represented by:

$$
\left(\bar{X}_{1}-\bar{X}_{2}\right)=\left|\begin{array}{r}
0.210 \\
1.154 \\
-1.402 \\
-0.331
\end{array}\right|
$$

It allows to send the identification of the four factors:

$$
a=\left(\bar{X}_{1}-\bar{X}_{2}\right) S^{-1}=\left|\begin{array}{r}
1.828 \\
1.281 \\
-1.307 \\
-0.096
\end{array}\right|
$$

The discriminant function became:

$$
Z=1.828 X_{1}+1.281 X_{2}-1.307 X_{3}-0.096 X_{4}
$$

The limit value (cut-off rate), according to which discriminate companies between the two groups under consideration, is obtained by calculating the middle value between the average of the score, relating to the two status:

$$
\bar{Z}_{c}=\frac{\left(\bar{Z}_{1}+\bar{Z}_{2}\right)}{2}
$$

where $\bar{Z}_{c}$ is the threshold incognito; $\bar{Z}_{1}$ is the average score of the healthy group; and $\bar{Z}_{2}$ is the average score of the group insolvent.

In the present example, this value is equal to: 


$$
\bar{Z}_{c}=\frac{(2.309-1.157)}{2}=0.579
$$

Comparing their scores with the cut-off, it comes finally to the qualification of enterprise insolvent, if it has a score lower than the threshold or enterprise healthy, if it has a score higher than the threshold value.

\section{Conclusions}

In light of the current economic situation, companies cannot shirk from implementing forms of management in raising the degree of stability of business results and reduce their risk of default. To this end, the company management has the ability to borrow the techniques of risk management normally adopted in banks, making the upright and additions necessary because of operational peculiarities that distinguish the company not to belong to the banking system. In light of this, the present paper provides another piece of knowledge of the framework by using discriminant analysis of Altaman to a panel of automotive companies to determine a Zeta threshold which can predict their insolvency.

\section{References}

Altman, E. I., \& Narayanan, P. (1997). Business failure classication models: An international survey. In F. Choi (Ed.), International accounting (2nd ed.). New York: Wiley.

Altman, E., Resti, A., \& Sironi, A. (2005). Loss given default: The next challenge in credit risk management. Londra: Risk Books. Anderson, R., \& Sundaresan, S. (1996). Design and valuation of debt contracts. The Review of Financial Studies, 9, 37-68.

Beaver, W. H. (1966). Financial ratios and predictors of failure, empirical research in accounting: Selected studies. Supplement to Journal of Accounting Research, 4, 71-111.

Bilderbeek, J. (1979). An empirical study of the predictive ability of financial ratios in the Netherlands. Zeitschrift Für Betriebswirtschaft, 5, 388-407.

Black, F., \& Cox, J. C. (1976). Valuing corporate securities: Some effects of bond indenture provisions. Journal of Finance, 31(2), 351-367.

Blum, M. (1974). Failing company discriminant analysis. Journal of Accounting Research, 12(1), 1-25.

Deakin, E. (1972). A discriminant analysis of predictors of business failure. Journal of Accounting Research, 10(1), $167-179$.

Edmister, R. (1972). An empirical test of financial ratio analysis for small business failure prediction. Journal of Financial and Quantitative Analysis, 7, 1477-1493.

Fisher, R. A. (1936). The use of multiple measurements in taxonomic problems. Annals of Human Genetics, 7(2), $176-188$.

Geske, R. (1977). The valuation of corporate liabilities as compound options. Journal of Financial and Quantitative Analysis, 12(4), 541-552.

Gombola, M., Haskins, M., Ketz, J., \& Williams, D. (1987). Cash flow in bankruptcy prediction. Financial Management, 16(4), 55-65.

Grunert, J., Norden, L., \& Weber, M. (2005). The role of non-financial factors in internal credit ratings. Journal of Banking and Finance, 29, 509-531.

Hull, J., \& White, A. (2000). Valuing credit default swaps I: No counterparty default risk. Journal of Derivatives, 8, 29-40.

Jarrow, R. A., Lando, D., \& Turnbull, S. M. (1997). A Markov model for the term structure of credit risk spreads. The Review of Financial Studies, 10(2), 481-523.

Kim, I. J., Ramaswamy, K., \& Sundaresan, S. (1993). Does default risk in coupons affect the valuation of corporate bonds? A contingent claims model. Financial Management, 40, 117-131.

Lando, D. (1998). On Cox processes and credit risky securities. Review of Derivatives Research, 2, 99-120.

Lehmann, B. (2003). Is it worth the while? The relevance of qualitative information in credit rating (Working Paper presented at the EFMA 2003 Meetings, Helsinki).

Leland, H. E., \& Toft, K. B. (1996). Optimal capital structure, endogenous bankruptcy, and the term structure of credit spreads. Journal of Finance, 5, 987-1019. 
Longstaff, F. A., \& Schwartz, E. S. (1995). A simple approach to valuing risky fixed and floating rate debt. Journal of Finance, 50, 789-819.

Lussier, R. N. (1995). A non-financial business success versus failure prediction model for young firms. Journal of Small Business Management, 33(1), 8-20.

Martin, D. (1977). Early warning of bank failure: A logit regression approach. Journal of Banking and Finance, 1, $249-276$.

Merton, R. C. (1974). An intertemporal capital asset pricing model. Econometrian, 41(5), 867-887.

Micha, B. (1984). Analysis of business failures in France. Journal of Banking and Finance, 8(2), 281-291.

Sironi, A., Resti, A., \& Rischio, E. (1999). Value in the banks (2nd ed.). Milano: Egea.

Taffler, R. J., \& Tisshaw, H. (1977). Going, going, gone-Four factors which predict. Accountancy, 88, 50-54.

West, R. C. (1985). A factor-analytic approach to bank condition. Journal of Banking and Finance, 9, 253-266. 